\title{
Mosaic Turner syndrome associated with schizophrenia
}

Sook Young Jung, MD', Joo Won Park', Dong Hyun Kim, MD', Yong Hoon Jun, $\mathrm{MD}^{1}$, Jeong Seop Lee, MD', Ji Eun Lee, MD ${ }^{1}$

${ }^{1}$ Department of Pediatrics, Inha University Hospital, Inha University School of Medicine, Incheon, ${ }^{2}$ Inha University School of Medicine, Incheon, ${ }^{3}$ Department of Psychiatry, Inha University Hospital, Inha University School of Medicine, Incheon, Korea

Received: 12 September, 2013

Revised: 7 October, 2013

Accepted: 26 October, 2013

Address for correspondence: Ji Eun Lee, MD

Department of Pediatrics, Inha University Hospital, Inha University School of Medicine, 27 Inhang-ro, Jung-gu, Incheon 400-711, Korea

Tel: +82-32-890-3617

Fax: +82-32-890-2844

E-mail: anicca@inha.ac.kr
Turner syndrome is a sex-chromosome disorder; occurring in 1 in 2,500 female births. There are sporadic few case reports of concomitant Turner syndrome with schizophrenia worldwide. Most Turner females had a 45,X monosomy, whereas the majority of comorbidity between Turner syndrome and schizophrenia had a mosaic karyotype $(45, \mathrm{X} / 46, \mathrm{XX})$. We present a case of a 21 -year-old woman with Turner syndrome, mosaic karyotype $(45, \mathrm{X} / 46, \mathrm{XX})$, showing mental retardation, hypothyroidism, and schizophrenia. HOPA gene within Xq13 is related to mental retardation, hypothyroidism, and schizophrenia. Our case may be a potential clue which supports the hypothesis for involvement of genes on $X$ chromosome in development of schizophrenia. Further studies including comorbid cases reports are need in order to discern the cause of schizophrenia in patients having Turner syndrome.

Keywords: Turner syndrome, Schizophrenia, X chromosome, Mosaicism

\section{Introduction}

Turner syndrome (TS) is relatively well-known sex chromosomal disorder that occurs in about $1 / 2,500$ live newborn female ${ }^{1)}$. TS is genetically caused by 45 , X monosomy (60\%), $45, \mathrm{X} / 46, \mathrm{XX}$ mosaicism (30\%), or other structural abnormality of X chromosome (10\%). It is well known that TS individuals usually are affected 3 somatic systems of skeletal, reproductive, and lymphatic. The specific neuropsychological deficits associated with TS include mild mental retardation, attentional problems, memory impairments, visuospatial processing problems, deficits in fear recognition, anxiety, impairments in social cognition, and motor functioning problems $s^{2}$.

Psychosis is relatively rare in TS female, but some authors have hypothesized that psychosis can be associated with $\mathrm{TS}^{3}$. No defined psychiatric condition has been traditionally related to TS, and TS is not mentioned in DSM-IV (Diagnostic and Statistical Manual of Mental disorders, 4th edition). Less is known about the development of psychosis in female TS.

Here, we report a sporadic case of a young woman with mosaic TS who developed psychosis diagnosed as schizophrenia.

\section{Case report}

A 21-year-old woman with TS was admitted because of auditory hallucinations and altered behavior for last 2 months. At the age of 13 years, she was first diagnosed with TS, mosaic karyotype 45,X/46,XX, combined by central obesity, hyperlipidemia, and type 2 diabetes mellitus. Also, she had been diagnosed concomitant with idiopathic central diabetes insipidus presenting polyuria ( $4 \mathrm{~L} /$ day) and polydipsia $\left(4-5 \mathrm{~L} /\right.$ day) for 1 year ${ }^{4}$. A water deprivation test showed central diabetes insipidus, and the initial finding of sellar magnetic resonance imaging (MRI) showed a thickening of the pituitary stalk with normal high signal intensity in the posterior pituitary gland. She had been managed with metformin, estrogen, and oral 1-deamino-8-D-arginine vasopressin, to which she had maintained well with about $2 \mathrm{~L}$ of 
daily urine volume. Follow-up MRI imaging had taken 2 years later demonstrated a nearly normal pituitary stalk thickness ${ }^{4}$.

At the age of 14 years, she had been treated with additional drug, levothyroxine due to Hashimoto's thyroiditis induced primary hypothyroidism. At the age of 18 years, her intelligence quotient (IQ) score was 52, suggestive of mild mental retardation, while her social quotient was at a level of 8 years. After graduated high school, she entered a vocational school for mentally disabled people. In school, she volunteered for a class senator, attended school punctually at any situation. She actively talked in school, so she earned the nickname 'radio'. She was active and honest daughter who lives with parents and younger brother. There was no history of alcohol or drug abuse. None of family members had psychiatric illness or mental retardation.

Before 2 months prior to admission, she suddenly avoided to talk and go to school and redundantly wanted to sleep without social interaction. She developed excessive daytime sleepiness and bizarre behavior with auditory hallucination 2 weeks ago. After taking oral medication prescribed by a psychiatric clinic, her symptoms including insomnia, visual and auditory hallucination were exacerbated. On mental status examination at admission, she showed poverty of speech, dysarthria, anxious mood, auditory hallucination, visual hallucination, persecutory delusion, social withdrawal, soliloquy, avolition, and aggressive behavior. Her orientation was intact for time, place, and person.

At admission to our hospital, the patient's height was $145 \mathrm{~cm}$ (percentile $<3$ th) and her weight was $51.5 \mathrm{~kg}(25 \mathrm{th}<$ percentile $<50$ th). Her body mass index was $24.5 \mathrm{~kg} / \mathrm{m}^{2}$. She had a blood pressure of $123 / 82 \mathrm{mmHg}$, pulse of 103 beats per minute, respiration rate of 18 breaths per minute, and a temperature of $36.8^{\circ} \mathrm{C}$. On physical examination, typical somatic features including dysmorphic face, webbed neck, low hairline, broad chest, and cubitus valgus were observed. Neurological examinations were normal. Laboratory findings revealed serum glucose, $107 \mathrm{mg} / \mathrm{dL}$ (normal, 70-100 mg/dL); glycosylated hemoglobin, 6.8\% (normal, 4.0\%-6.0\%); normal free T4 level, $1.96 \mathrm{ng} / \mathrm{dL}$ (normal, $0.80-1.90 \mathrm{ng} / \mathrm{dL}$ ); and thyroid-stimulating hormone, $0.80 \mathrm{mIU} / \mathrm{L}$ (normal : 0.17-5.65 mIU/L); sodium, $133 \mathrm{mEq} / \mathrm{L}$ (normal, 133-145 mEq/L); potassium, $3.8 \mathrm{mEq} / \mathrm{L}$ (normal, 3.5-5.5 mEq/L); chloride 96, mEq/L (normal, 95-110 $\mathrm{mEq} / \mathrm{L}$ ); serum osmolarity, $280 \mathrm{mOsm} / \mathrm{kg}$ (normal, 288-302 $\mathrm{mOsm} / \mathrm{kg}$ ); urine osmolarity, $464 \mathrm{mOsm} / \mathrm{kg}$ (normal, 300-900 $\mathrm{mOsm} / \mathrm{kg}$ ). The last follow-up MRI showed no significant interval change of pituitary stalk thickening compared to previous MRI finding and no abnormal pituitary mass or brain parenchymal abnormality. After diagnosed as having psychotic disorder, she was started on oral ziprasidone, which was gradually increased. She showed significant improvement after 1 month, but her symptoms were waxing and waning without full remission. She is under regular follow-up for the last 10 months.

\section{Discussion}

The majority of individuals with TS are known to have normal intelligence with normal verbal abilities ${ }^{5)}$. On the other hand, several studies have revealed that TS patients may show decreased full-scale IQ, and have selective impairments with regard to visuo-spatial processing and visuo-perceptual skills ${ }^{2)}$. The risk of memory and attention problems and the risk of developing autism and attention deficit hyperactivity disorder in TS are higher than in the normal population ${ }^{6,7)}$. Furthermore neuroanatomical imaging provided evidence of abnormalities in several brain structures, including the parietal lobe, amygdala, hippocampus, and orbito-frontal cortex ${ }^{8)}$.

Schizophrenia is a complex genetic disorder with a prevalence of about $1 \%{ }^{9}$. Genetic factors play an important role in the developing schizophrenia. The risk of schizophrenia is 3 times higher in people with mild learning disability than in the general population and chromosomal abnormalities are increased. In general, TS is found about three times more often in female schizophrenics than in the general female population ${ }^{3,10)}$. Previous researches studying sex chromosome abnormalities in schizophrenic subjects have investigated the role of extra-X chromosome in Klinefelter syndrome $(47, \mathrm{XXY})$ or triple $\mathrm{X}$ $(47, \mathrm{XXX})$

Recently the hypothesis of a locus within the pseudoautosomal region of the $\mathrm{X}$ chromosome conferring susceptibility to schizophrenia has been studied. DeLisi et al. ${ }^{11)}$ reported that neuropsychiatric findings of XXY karyotype individuals with schizophrenia result from genes within the pseudoautosomal region in the $\mathrm{X}$ chromosome and tend to avoid normal extra- $\mathrm{X}$ chromosome inactivation. These regions may produce their gene products in excess, influencing normal brain growth and differentiation. On the other hand nonpseudoautosomal regions of the X chromosome, mapping to a locus on Xp21, have been associated with the development of schizophrenia ${ }^{12)}$.

TS may lead to an increased risk for schizophrenia. To our knowledge, there are few published cases of schizophrenia in TS individuals due to the rarity of both disorders, total 20 cases have been described in the English literature ${ }^{10,13)}$. Interestingly, most TS females had a 45,X nonmosaic karyotype, whereas the majority (19/20) of comorbidity between TS and schizophrenia had a mosaic karyotype $(45, \mathrm{X} / 46, \mathrm{XX})$. Thus, it has been suggested that the potential of gene dose-effect might be associated with abnormal expression of an X chromosome gene product, which have susceptibility for schizophrenia in $\mathrm{TS}^{10)}$.

Recently Roser and Kawohl ${ }^{13)}$ published a case report on TS, schizophrenia, mental retardation, and hypothyroidism associated with polymorphism of the human opposite paired (HOPA) gene, located on Xq13. The HOPA gene is associated with mental retardation, thyroid dysfunction, and neuropsychiatric disorders. HOPA gene product belongs to the thyroid receptor associated protein that codes for a coactivators for thyroid hormone receptor ${ }^{14)}$. Because the HOPA gene is expressed throughout the central nervous system in the period of fetal development, the abnormality in the HOPA gene is hypothesized to raise risk for schizophrenia ${ }^{15)}$. Also, an association between the HOPA polymorphism and mental retardation was reported ${ }^{15,16)}$. The Xq13 region, including the 
$\mathrm{X}$ inactivation center and a gene escaping $\mathrm{X}$ inactivation, may contribute to the $\mathrm{X}$ inactivation process in addition to the pathogenesis of schizophrenia in $\mathrm{TS}^{17}$.

The findings for our TS patient, who had the mosaic karyotype, were very similar to the clinical findings, such as mental retardation, schizophrenia, and hypothyroidism in the case reported by Roser and Kawohl ${ }^{13)}$. Hypothyroidism in our case was caused by Hashimoto thyroiditis. Several studies reveled that schizophrenia is linked with some autoimmune diseases, especially autoimmune thyroid disease, type 1 diabetes, celiac disease, rheumatoid arthritis ${ }^{16,18)}$. She might be the similar case of comorbid TS and schizophrenia, mental retardation, hypothyroidism, which speculated the genetic possibility such as the HOPA gene on the $\mathrm{X}$ chromosome might be involved in the development of schizophrenia.

In Korea, only two cases with both chronic psychosis and TS were reported $^{19,20)}$. Both patients had the mosaic karyotype of 45,X/46,XXp- without mental retardation as well.

Further studies, including comorbid case reports are needed in order to discern the pathogenesis of schizophrenia in TS. It is important for practitioners to understand the clinical spectrum and the natural courses, including the development of schizophrenia, in mosaic TS.

\section{Conflict of interest}

No potential conflict of interest relevant to this article was reported.

\section{References}

1. Boman UW, Moller A, Albertsson-Wikland K. Psychological aspects of Turner syndrome. J Psychosom Obstet Gynaecol 1998;19:1-18.

2. Lynn PM, Davies W. The $39, \mathrm{XO}$ mouse as a model for the neurobiology of Turner syndrome and sex-biased neuropsychiatric disorders. Behav Brain Res 2007;179:17382.

3. Kawanishi C, Kono M, Onishi H, Ishii N, Ishii K. A case of Turner syndrome with schizophrenia: genetic relationship between Turner syndrome and psychosis. Psychiatry Clin Neurosci 1997;51:83-5.

4. Kang B, Sung HU, Kim BK, Park SY, Kim SK, Kwon YS, et al. A case of Turner syndrome associated with idiopathic central diabetes insipidus. J Korean Soc Pediatr Endocrinol 2011;16:56-60.

5. Murphy DG, DeCarli C, Daly E, Haxby JV, Allen G, White BJ, et al. X-chromosome effects on female brain: a magnetic resonance imaging study of Turner's syndrome. Lancet 1993;342:1197-200.

6. Downey J, Ehrhardt AA, Gruen R, Bell JJ, Morishima A. Psychopathology and social functioning in women with Turner syndrome. J Nerv Ment Dis 1989;177:191-201.

7. Romans SM, Stefanatos G, Roeltgen DP, Kushner H, Ross
JL. Transition to young adulthood in Ullrich-Turner syndrome: neurodevelopmental changes. Am J Med Genet 1998;79:140-7.

8. Good CD, Lawrence K, Thomas NS, Price CJ, Ashburner J, Friston KJ, et al. Dosage-sensitive X-linked locus influences the development of amygdala and orbitofrontal cortex, and fear recognition in humans. Brain 2003;126(Pt 11):243146.

9. Kessler RC, McGonagle KA, Zhao S, Nelson CB, Hughes M, Eshleman S, et al. Lifetime and 12-month prevalence of DSM-III-R psychiatric disorders in the United States. Results from the National Comorbidity Survey. Arch Gen Psychiatry 1994;51:8-19.

10. Prior TI, Chue PS, Tibbo P. Investigation of Turner syndrome in schizophrenia. Am J Med Genet 2000;96:3738.

11. DeLisi LE, Maurizio AM, Svetina C, Ardekani B, Szulc $\mathrm{K}$, Nierenberg J, et al. Klinefelter's syndrome (XXY) as a genetic model for psychotic disorders. Am J Med Genet B Neuropsychiatr Genet 2005;135B:15-23.

12. Zatz M, Vallada H, Melo MS, Passos-Bueno MR, Vieira AH, Vainzof M, et al. Cosegregation of schizophrenia with Becker muscular dystrophy: susceptibility locus for schizophrenia at Xp21 or an effect of the dystrophin gene in the brain? J Med Genet 1993;30:131-4.

13. Roser P, Kawohl W. Turner syndrome and schizophrenia: a further hint for the role of the X-chromosome in the pathogenesis of schizophrenic disorders. World J Biol Psychiatry 2010;11(2 Pt 2):239-42.

14. Kirov G, Georgieva L, Nikolov I, Zammit S, Jones G, Poriazova N, et al. Association analysis of the HOPA12bp polymorphism in schizophrenia and manic depressive illness. Am J Med Genet B Neuropsychiatr Genet 2003;118B:16-9.

15. Eaton WW, Byrne M, Ewald H, Mors O, Chen CY, Agerbo E, et al. Association of schizophrenia and autoimmune diseases: linkage of Danish national registers. Am J Psychiatry 2006;163:521-8.

16. Malhotra S, Kumar P, Kaur N, Bhatia MS, Hans C. Schizophrenia and autoimmune disorders: is there a link? Delhi Psychiatr J 2012;15:385-93.

17. Brown CJ, Ballabio A, Rupert JL, Lafreniere RG, Grompe $\mathrm{M}$, Tonlorenzi R, et al. A gene from the region of the human $\mathrm{X}$ inactivation centre is expressed exclusively from the inactive X chromosome. Nature 1991;349:38-44.

18. DeLisi LE, Smith AB, Razi K, Stewart J, Wang Z, Sandhu HK, et al. Investigation of a candidate gene for schizophrenia on Xq13 previously associated with mental retardation and hypothyroidism. Am J Med Genet 2000;96:398-403.

19. Choi YT, Cheon JS. An organic delusional disorder in association with Turner's syndrome. J Kosin Med Coll 1993;9:97-104.

20. Lee HJ, Kim JG. Chronic psychosis in Turner's syndrome. J Korean Neuropsychiatr Assoc 1993;32:266-72. 